\title{
IF HR WERE REALLY STRATEGICALLY PROACTIVE: PRESENT AND FUTURE DIRECTIONS IN HR'S CONTRIBUTION TO COMPETITIVE ADVANTAGE
}

\author{
Wayne Brockbank
}

\begin{abstract}
Current business conditions mandate greater competitive advantage from HR agendas and processes. To add greater competitive advantage, HR must contribute strategic value against criteria from customer and capital markets. HR can add strategic value either reactively or proactively. In its strategically reactive mode, HR assumes the existence of a business strategy and adds value by linking HR practices to the business strategy and by managing change. In its strategically proactive mode, HR creates competitive advantage by creating cultures of creativity and innovation, by facilitating mergers and acquisitions, and by linking internal processes and structures with ongoing changes in the marketplace. This article defines and describes these specific practices through which HR can contribute to greater competitive advantage. (C) 1999 John Wiley \& Sons, Inc.
\end{abstract}

\section{Introduction}

At the end of this special issue of Human Resource Management on HR best practices, it is appropriate to review the evolution of the HR field and to examine its future high valueadded practices. Over the last few years, knowledge of the human side of business has dramatically increased. While HR practices substantially lag behind HR knowledge, practices in the HR field are evolving at an accelerated rate, and the lag between knowledge and practices appears to be shrinking. The field is learning better how to learn and more quickly apply what has been learned.

This article begins by arguing that HR's centrality to business success has never been so pronounced. It then provides a framework for examining the field's evolution in adding competitive advantage. It concludes with an examination of the progress of the field from being operationally reactive to adding greater value by being strategically proactive. The stages of evolution between these two extremes will be defined and examined in some detail.

While this article is not intended to be a quantitative analysis of the field's evolution, it is also not intended to be a theoretical essay. Rather, this article draws on the author's methodological observations with thoughtful HR professionals from 66 outstanding companies (see Appendix). Between 1990 and 1998, the author interviewed key HR professionals and, in most cases, senior line executives about the logic, strategic framing, and best practices of their HR organizations. This article is based on insights ${ }^{1}$ gained from these companies.

\section{Emergence of HR's Importance}

Substantial empirical as well as anecdotal evidence supports the notion of HR's growing importance. In 1992, 2,961 executives, consultants, and academicians participated in a 
In addition to direct and indirect empirical evidence concerning the emerging importance of $H R$, the field is rife with supporting anecdotal evidence. study on the future of HR (Towers Perrin, 1992). Twenty-five percent of the respondents stated that the first or second most important goal for HR was that it be more strongly linked to business strategy. Thirty-two percent stated that this goal would be adequately accomplished by the year 2000. Line executives alone projected a $10 \%$ increase in the importance of ensuring that HR be linked to business strategy, whereas HR respondents projected only a $5 \%$ increase.

In three rounds of data gathering in 1988 , 1992 , and 1997 , more than 20,000 individuals participated in the Human Resource Competency study at the University of Michigan (Brockbank, Ulrich, \& James, 1997). In 1988, the HR departments of the highest performing firms had a strong and equal focus on both the strategic and operational aspects of HR. In 1992 and again in 1997, firm performance was found to be higher as HR departments focused more on the strategic aspects of $\mathrm{HR}$ and relatively less on operational agendas. High performing firms reduced the time and effort spent on operational HR activities so that they could focus on higher valued HR agendas. The alternative mechanisms for accomplishing the operational work done are discussed later in this article.

The seminal and ongoing work to date on the relationship between financial performance and HR practices has been conducted by Brian Becker and Mark Huselid (1998). In their study of 740 firms, they found that firms with greater intensity of HR practices had greater market value per employee. Specifically, they found that a standard deviation's increase in a firm's HR practices resulted in a $\$ 45,000$ increase in market value per employee. If a firm with 10,000 employees were to make such an improvement, the firm's market value would increase approximately half a billion dollars.

In addition to direct and indirect empirical evidence concerning the emerging importance of $\mathrm{HR}$, the field is rife with supporting anecdotal evidence such as the following:

1. The number of companies in which senior HR executives report to the CEO appears to be increasing.

2. CEOs in high performing firms are giving greater focus to HR issues (General Electric, Allied Signal,
Hewlett Packard, Herman Miller, Sears, Disney, Intel, Texas Instruments, Ford).

3. Improvement in firm performance is increasingly attributed to HR's contributions (Sears, Ford, Baxter International, Harley Davidson, Quantum, Unilever, Arco).

Finally, the fact that the membership of the Society of Human Resource Management has reached 120,000 in 1999 and that the membership of Human Resource Planning Society has increased 50\% between 1992 and 1997 are further indirect evidence that HR professionals are finding a greater need for knowledge and professional development than ever before.

This increase in the importance of HR has not happened accidentally. Rather, these trends are a function of specific changes in the business environment. With the increased rate of transnational wealth, a firm's ability to compete in a global environment becomes increasingly contingent on having the right people, transnational learning systems, and optimal measures and incentives for measuring and rewarding individual and firm effectiveness. Pressures from competitors, shareholders, and customers require that people create new products, services, and processes ahead of the competition. In a world of hyper speed, people ultimately create changes in microchips, computers, disk drives, printers, and grocery products. As the workplace becomes increasingly diverse (Cox, 1993; Thomas, 1996), companies must leverage the full capabilities of all employees regardless of differences in demographics, different levels, departments, functions, regions, and disciplines. The explosion of service vocations and the reliance of these vocations on people has likewise propelled the human side of the business equation to the forefront. In 1998 the dollar volume of mergers and acquisitions in the United States was three times greater than ever before. Because people are required to conceptualize portfolio opportunities, identify merger and acquisition candidates, conduct due diligence and negotiations, and make new alliances work, the HR systems that provide and support people and influence their mindset and technological capabilities become increasingly 
important. This is especially true given that $65 \%$ of mergers and acquisitions fail to achieve their stated goals (Krallinger, 1997).

\section{Competitive Advantage: From the Past to the Future}

The human resource management field has responded to these conditions by conceptualizing and implementing higher value-added HR agendas. This section provides a general framework for analyzing current HR trends. It then extends the logic of the framework to assess the emerging generation of value-added HR agendas.

The distinction between the operational and strategic levels of HR has received considerable attention in the literature (Brockbank, Ulrich, \& James, 1997; Ulrich, 1997a). Operational HR activities generally refer to the routine, day-to-day delivery of HR basics. The strategic level of HR activity is more complex and involves five criteria:

- Long term-Is the activity conceptualized to add long term as opposed to short term value?

- Comprehensive-Does it cover the entire organization or isolated components?

- Planned-Is it thought out ahead of time and is it well documented or does it occur on an ad hoc basis?

- Integrated-Does it provide a basis for integrating multifaceted activities that might otherwise be fragmented and disconnected?

- High value-added-Does it focus on issues that are critical for business success or does it focus on things that must be done but are not critical to financial and market success?

In the last three or four years, the field has begun to use the term "proactive" as a criterion for HR success. Two issues may cloud the use of this concept. First, "proactive" is one of those words that is often a "feel good" word rather than one that actually describes what people do. For example, it is easy to agree on the importance of being proactive, but being proactive in "strategic" ways leads to very different activities than being proactive in "operational" ways. Second, as "proactive" has become popular, "reactive" has become less popular. While there are times to be proactive, there are clearly times to be reactive. Being quickly reactive against strategic criteria can often create substantial competitive advantage.

Combining these two dimensions yields a framework around which the HR field may organize its thinking about the past, present, and future of HR.

Before examining each quadrant in detail, I will provide an overview of the model including a brief description of each quadrant and a sample of associated activities.

Operationally reactive $\mathrm{HR}$ focuses on implementing the basics; it addresses the question of, given the day-to-day demands of the business, how should HR react to ensure that the basics are addressed? Such activities include administering benefits, maintaining market-based salary grids, hiring entry level employees, and providing basic skill training.

Operationally proactive HR improves on the design and delivery of the HR basics; it addresses the question of how HR can improve the quantity and quality of the HR basics before problems occur. Such activities include
While there are times to be proactive, there are clearly times to be reactive.

\begin{tabular}{|l|l|l|}
\hline & REACTIVE & \multicolumn{1}{|c|}{ PROACTIVE } \\
\hline STRATEGIC & Makes strategy happen & $\begin{array}{l}\text { Creates strategic } \\
\text { alternatives }\end{array}$ \\
\hline OPERATIONAL & Implements the basics & Improves the basics \\
\hline
\end{tabular}


As HR creates this kind of value in a timely manner, it contributes to its firm's competitive advantage. reengineering HR processes, applying TQM principles to HR activities, and ensuring positive morale in the workforce.

Strategically reactive $\mathrm{HR}$ focuses on implementing the business strategy; that is, given a clearly formulated business strategy (e.g., growth, new product, innovation, cycle time reduction, new market entry), how can HR help support its successful implementation? Such activities include identifying and developing the technical knowledge, tactical skills, and business culture that are consistent with the demands of the business strategy. They may also include facilitating change management and organizing HR into service centers.

Strategically proactive HR focuses on creating future strategic alternatives. Such activities include creating a culture of innovation and creativity; identifying merger and acquisition possibilities; and creating internal capabilities that continually track and align with the marketplace for products, markets, and capital with their respective lead indicators.

This framework provides a basis not simply for describing alternative arenas for HR involvement; it also suggests a measuring stick against which to assess the progress of HR's value added at both the discipline and firm levels. This matrix from Table I may be reconfigured to create a linear scale for measuring HR as competitive advantage.

Competitive advantage entails having the capability to provide better products, services, or financial returns than the competition does.
HR should help its firm create value in the marketplaces for said capital, products, and services before its competitors do. As HR creates this kind of value in a timely manner, it contributes to its firm's competitive advantage. Thus, some categories of HR practices create greater competitive advantage than do others. This is indicated by the HR Competitive Advantage Index in Table I. As discussed above, the strategic versus operational dimension suggests that HR creates competitive advantage when it creates, over the long run, greater value than its competitors' HR activities, optimizes the entire organization instead of subcomponents, and focuses the firm on issues that are critical for market success. The proactive versus reactive dimension suggests that value creating HR activities be done before they are done by the competition. It requires that a firm's HR function creates a temporal window within which the firm can dictate competitive rules and command monopoly position. The combination of these two dimensions into the HR Competitive Advantage Index enables HR to calibrate the extent to which an HR practice or set of practices creates strategic value before the competition. Thus, an HR department increases its potential to create competitive advantage as it moves from being operationally reactive to being strategically proactive.

Given the pressures on HR to add greater value before the competition and the emerging arsenal of HR practices, it follows that the above index may be superimposed onto a product life-cycle logic (see Figure 1).

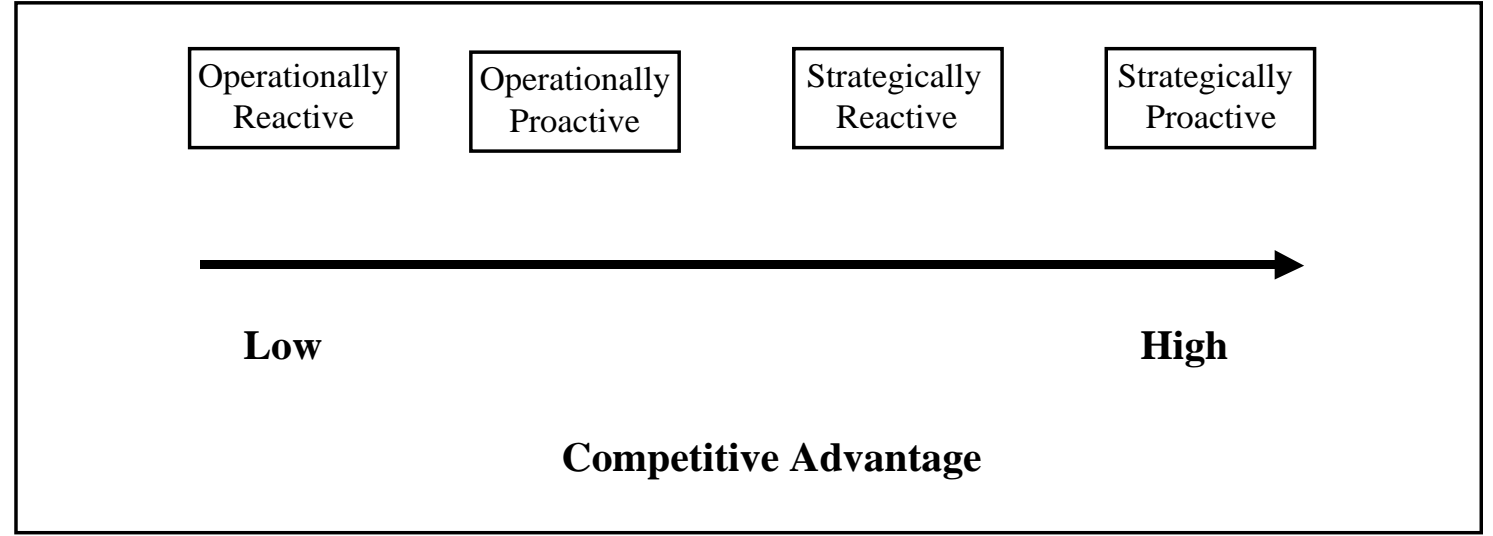

FIGURE 1. HR competitive advantage index. 


\section{HR Competitive Advantage}

Placing the HR competitive advantage index into a life-cycle logic provides a useful logic for assessing the extent to which HR creates true competitive advantage (see Figure 2). Virtually all firms have HR departments or functions that provide operationally reactive HR practices and processes. Even the most elementary business requires that people are paid, benefits are administered, people are hired, and basic skills are ensured.

Operationally proactive HR agendas were generally the state-of-the-art in the late 1980s and early 1990s. Reacting to the recognition of the unacceptable cost of hierarchical bureaucracy (Ashkenas, Ulrich, Jick \& Kerr, 1995) and the recession of 1991-1992, many companies required reductions in the proportion of their staff functions. The mandate of "more with less" became the order of the day. Thus, a dominant agenda of conferences, seminars, and professional publications focused on the application of reengineering and Total Quality Management (TQM) to HR (Yeung \& Brockbank, 1995). Service centers were born (Ulrich, 1995). Today one must look long and hard to find conferences and articles on these topics. Late adopters are a relatively small proportion of the total population, and the demand for HR expertise in these arenas is shrinking.
The HR agenda of the late nineties - the state-of-the-art-is linking HR to the business strategy: Given the business strategy, what is HR's role in making the strategy happen? Again, articles, seminars, conferences, and university-based executive programs abound to help HR play a more powerful and effective role in strategy implementation. Major consulting firms have established specialty consulting in HR strategy, change management, culture change, and other related areas (e.g., Arthur Anderson, Deloitte and Touche, Bain, McKinsey, Mercer, WatsonWyatt, etc.). In addition, many companies including Sears, Lucent, Coca Cola, Dow Corning, and General Motors have made aligning HR with business strategy a successful HR priority.

Relatively few early adopters are venturing into the realm of strategically proactive HR. Nevertheless, there are clear examples of HR departments moving into this arena. Strategically proactive HR agendas include identifying portfolio requirements, selecting merger and acquisition candidates, creating institutional change capacity, building organizational cultures of radical innovation, and identifying social trends that can be parlayed into products and services. These activities represent the logical extension of the HR field. Those HR departments with the capability to do so will lead the field in creating competitive advantage.

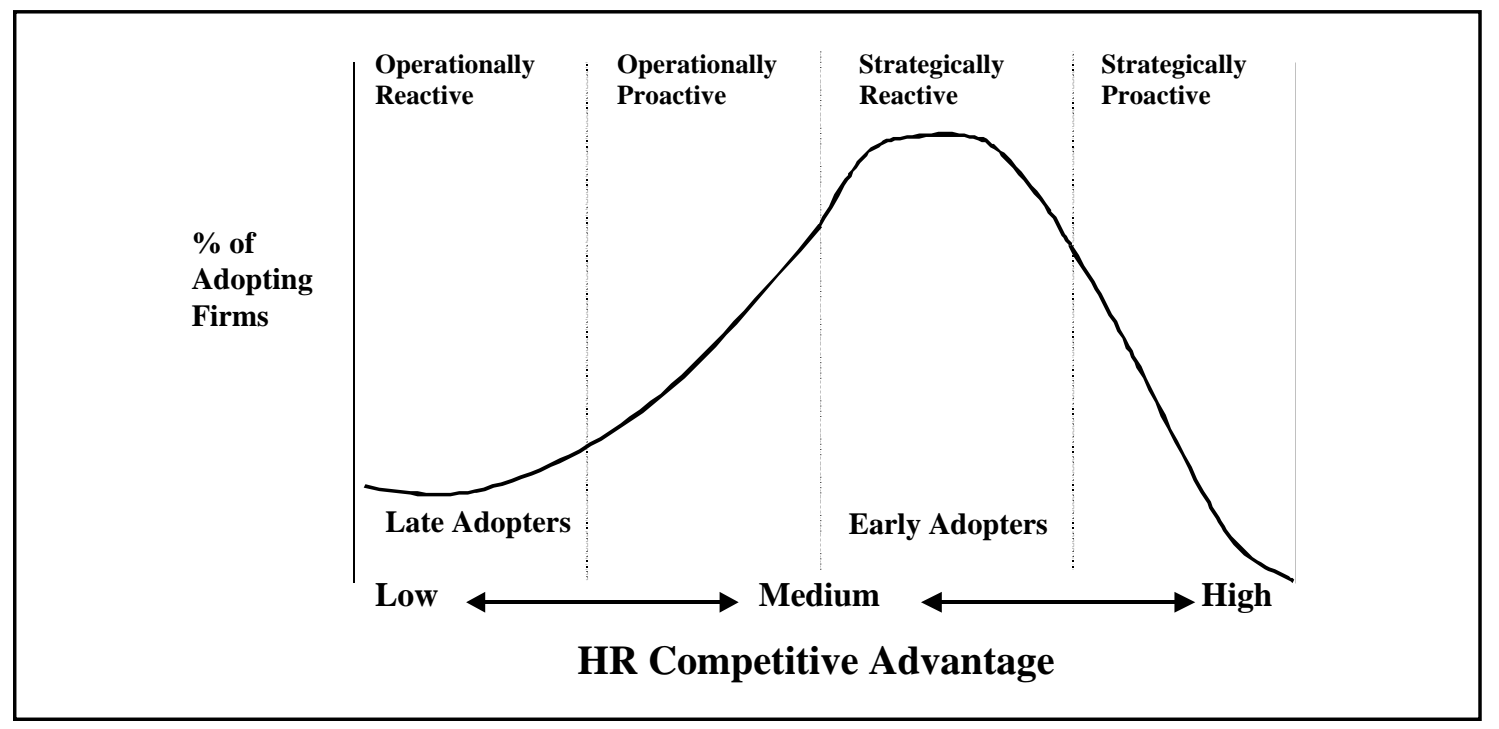

FIGURE 2. Lifecycle of HR Competitive Advantage 
By applying the principles of TQM, the HR field sought to improve the accuracy of its HR work.

\section{Application of the HR Competitive Advantage Index}

The remainder of this article examines each of the four levels of HR's competitive advantage with major focus on HR's role in being strategically reactive and strategically proactive.

\section{Operationally Reactive HR}

As Figure 1 suggests, relatively few firms are currently in the mode of adopting operationally reactive HR practices. The main reason is that virtually all firms already do the HR basics; that is, they pay employees, have benefits of some kind (even if nothing more than the processing of federal and state tax information), hire entry level employees, and ensure at least remedial competence through formal or on-the-job training. Even sole proprietors and partnerships ensure that these functions are carried out. The fact that the great majority of college level HR text books focus on this level of HR thinking evidences that this arena of HR involvement is a commodity (e.g., Cascio, 1995; Schuler, 1997). Without these activities a firm will fail, but with them, little competitive advantage is gained.

\section{Operationally Proactive HR}

Firms in the operationally reactive mode focus on improving the productivity of their HR departments and the quality of their HR practices. Much of the breakthrough work on improving quantitative and qualitative aspects of HR occurred in the late 1980s and early 1990s. Driven by global competition in the 1970s and 1980s, firms were required to improve productivity and efficiency. A major response was the emergence of reengineering that combined with information technology to enable the automated processing of considerable volumes of transactional HR work (Yeung \& Brockbank, 1995). During this time other practices took root that helped HR do more with less. These practices included outsourcing (e.g., benefit and payroll administration firms), work elimination (e.g., reducing steps in answering benefit inquiries), reallocation of activities to the line (e.g., having line man- agers handle grievances), and the creation of HR service centers (centralized transactional work processing centers). Firms such as Intel, Hewlett-Packard, Sears, Cisco Systems, Amoco, and Texas Instruments provided groundbreaking work in these arenas.

By applying the principles of TQM, the HR field sought to improve the accuracy of its HR work. Consistent with the requisites of TQM, during the 1990s the field made considerable progress in its ability to set clear standards of measurement for HR practices (Ulrich, 1997b; Yeung \& Berman, 1997; Wintermantel \& Mattimore, 1997). Alcoa and Motorola developed robust lists of measurements for productivity in HR functional areas including recruitment, benefits and salary administration, training and development, career management, diversity, health and safety, communications, and performance management. Employee attitude surveys that focused on the internal customers' perceptions of HR gained substantial popularity with virtually every HR-related consulting firm providing internal HR audits. HR mission statements abounded, which promised to "surprise and delight" internal customers and to provide "error-free HR work". Finally, to ensure that employee dissatisfaction would be addressed before major problems emerged, internal customers became more heavily involved in designing key elements of HR practices.

\section{Strategically Reactive HR}

HR may be strategically reactive in business strategy implementation through two dominant avenues: (1) supporting the execution of tactics that drive the long-term strategies and (2) developing the cultural and technical capabilities necessary for long-term success. HR may also assist in the process of strategy implementation by providing change management support for tactical activities.

Tactical Support. The capacity of HR to be strategically reactive assumes the presence of a business strategy with its accompanying operational tactics. With the firm's strategic and tactical logic in place, HR's role becomes relatively obvious. How many people do we need? Where do we get them? What training 
do they require? How do we measure and reward desired behaviors and results?

Creating the Strategy-Focused Culture. The second channel through which HR practices may be linked to business strategy is through the establishment of a powerful and strategically focused culture ${ }^{2}$ and in the continual availability of state-of-the-art technical knowledge and skills ${ }^{3}$. The process by which this linkage may be established can be divided into eight steps.

Step 1: Define the business unit for which the HR practices are being designed. Is the process used defining an HR strategy for a plant, business unit, division, sector, department, or for the company as a whole?

Step 2: Specify the key trends in the external business environment. What are the dominant trends that indicate key threats or opportunities? Trends among customers, competitors, informational technology, owners' expectations, regulatory requirements as well as product and process technologies must all be considered. Since it is difficult to define a company's culture around a large number of such trends, however, it is imperative that a clear and weighted prioritization be established among the frequently competing and contradictory requirements (Brockbank, 1995). The rationale for beginning with the environmental analysis instead of with the business strategy is threefold. First, the business strategy should be based on the environmental analysis. Second, it is useful practice for those who develop the businessbased human resource strategy (including but not limited to the firm's key HR professionals) to examine marketplace realities in a clear and focused manner. Third, many business strategies are not HR-friendly; that is, they are not formulated to facilitate the mindset and technical requirements of individuals who make strategy happen.

Step 3: Identify and prioritize the firm's sources of competitive advantage. The key issue here is identifying how the company is choosing to compete. Is it choosing to compete on the basis of cost, quality, speed, innovation, service, relationships, convenience, branding, and/or distribution? Since a firm's culture should be defined in a way to be consistent with these foundational strategic assumptions, it is necessary to have a clear sense of priority among these alternatives. In the automotive industry, for example, both cost and quality are important; however, if cost is assumed to be $90 \%$ and quality $10 \%$ of a firm's competitive focus, a different culture should dominate than if it is assumed that cost and quality should receive equal focus.

Step 4: Define the required culture (including specific behaviors) and technical knowledge and skill areas that the firm requires to create and support the sources of competitive advantage that were identified in Step 3. In the past few years, companies have moved beyond superficial culture definitions and are now specifying cultures and behaviors directly aligned with marketplace requirements. A sampling of such cultural definition includes restless creativity (Unilever), lean and unencumbered teamwork (Cathay Pacific Airways), and focused agility (Enron Corp). While the meaning and passion behind these constructs may not be accessible to the outsider, to those who develop and apply them, they convey definitions of culture that serve as key supporting elements of business strategy. Complementing the cultural competencies are the required technical competencies. With the ever-decreasing life span of technical knowledge and skills, cultural competencies become increasingly important. Nevertheless, a substantive base of technical knowledge and skills is warranted in virtually every industry.

Step 5: Identify the cultural characteristics that the firm should reduce or eliminate if it is to optimize competitive advantage. Such undesirable cultural traits might include being internally focused, slow, complacent, arrogant, oblivious to competitive realities, or risk averse.

Step 6: Design the HR practices that will have greatest impact on creating the desired culture. This can be accomplished by evaluating the extent to which each HR practice is aligned with the desired culture. If an HR practice is not aligned with the desired outcome, then an evaluation must be made about the extent to which the practice would have impact on creating the desired culture if it were aligned. It is useful at this stage to distinguish between traditional and nontraditional HR practices. Traditional HR practices are generally under the direct influence of most HR departments. They
In the past few years, companies have moved beyond superficial culture definitions and are now specifying cultures and behaviors directly aligned with marketplace requirements. 
HR's position at the proactive strategy table can be earned in two ways ... include staffing, performance management, financial and nonfinancial incentives, and training and development. Nontraditional HR practices, on the other hand, are those not generally under HR's direct influence, but which have substantial influence on the mindset and technical capabilities of the firm. Such practices include organization design, reengineering, office or plant layout, job design, leadership communications, information systems design, and customer contact programs. It is HR's task to ensure that both traditional and nontraditional HR practices are mutually consistent in influencing the human side of the business equation.

Identifying action plans for enhancing the technical knowledge and skills is relatively easy. Two questions must be addressed. Do a lot of people require them or few? Are these technical capabilities best acquired through training, though recruitment or through borrowing (in the form of consultants and other external vendors)?

Step 7: With these decisions made, the firm should establish action plans for detailed design of the HR processes. Who will do what, by when, with whom, with what resources? What will be the mechanism of reporting to line management?

Step 8: The final step specifies the means by which effectiveness of the entire process is measured. Are the HR practices successfully creating the strategically targeted cultural and technical capabilities?

This framework has been widely used by many companies such as Texas Instruments, Alcoa, General Motors, Coca Cola, ITT, Dow Corning, and Unilever as the logic and process by which to link HR practices to preestablished business strategies.

Management of Change. The third set of activities by which HR is strategically reactive is found in change management programs. Organizational development and other change management activities assist in the implementation of general strategies and/or specific tactics. Multiple frameworks for change management may be found in the literature. One that has appropriately received considerable recognition (Ulrich, 1997a) specifies seven critical success factors for change:
- Ensuring support from key executives

- Creating a shared need for change among those who live with the change, including both employees and management

- Ensuring a clearly articulated vision of the end-state of change

- Eliciting the commitment of key stakeholders to the change vision and to the steps necessary to achieve desired outcomes

- Leveraging the management and HR systems that support and drive the change

- Defining insightful measurement by which the progress of change can be monitored

- Establishing learning loops through which change efforts may ensure ongoing improvement and progress

While each of these phases contains much of what has been documented over the years' experience with change management, the primary utility of this model is the structuring of the many details of change management into compact bundles of actions. When applied to the implementation of specific strategies and tactics, this model can assist HR professionals in reacting to strategic direction and tactical initiatives. It is also possible, however, for companies to use these steps not simply to implement change but to develop the capacity for change. This potentiality will be addressed in the next section.

\section{Strategically Proactive HR}

As discussed above, being strategically proactive prompts the question, "What is HR's role in creating strategic alternatives?" HR's position at the proactive strategy table can be earned in two ways: (1) by learning enough about the other functional areas (i.e., finance, marketing, production) to be able to contribute to business discussions in the terms and concepts of the other functional areas, and (2) by expanding and enriching the parameters of HR agendas through which strategic alternatives may be defined and created. To be a full partner at the strategy table, HR professionals must be capable of contributing at both levels. In the first, HR 
professionals create business alternatives through their ad hoc knowledge of other fields; in the second, they create business alternatives through the application of HR assumptions and logic.

As suggested in Figure 2, a relatively small number of HR departments are early participants in strategically proactive HR activities, so few reap the resultant competitive advantage. As an initial foray into the arena of strategically proactive $\mathrm{HR}$, this article suggests three avenues through which HR can be strategically proactive: (1) creating the culture of creativity and innovation, (2) being involved in the full breadth of mergers and acquisition activities, and (3) creating internal capabilities based on future external environmental requirements.

HR can proactively add strategic value by enhancing the innovative capability of the firm. In so doing HR can improve the probability that the firm will bring to market new products and services before the competition, thereby reaping the pricing benefits of shortterm monopoly market positions. The firm's innovative capability may be evidenced in providing new and improved products and services, reducing costs, improving quality, entering new businesses, and discovering new applications for existing products in either existing or potential markets. As HR plays a central role in these activities, it enhances the firm's ability to create market turbulence to which its competitors must respond rather than being in the position of responding to the rule-defining turbulence that its competitors may create.

Of course, no set of practices can guarantee that creativity will occur in a given situation. Innovation may not occur even where the conditions appear correct. Likewise, serendipitous innovation may occur where least expected. A reasonable expectation is that HR will enhance the firm's probability that innovative breakthroughs will occur.

Books and articles contain hundreds of anecdotes and stories about innovation in organizational settings (see, for example, Robinson \& Stern, 1997; Isaksen, 1987; Drucker, 1985). Anecdotes and stories may inspire and reveal the possibilities, but they often fail to make explicit the levers that organizational leaders apply to increase the likelihood of innovation. Underlying nearly all discussions of creative breakthroughs in corporations is the conclusion that HR practices play a major role in the success of virtually every innovative organization.

To enhance the probability of innovation, two preconditions generally must exist. First, there must be a conscious decision by key decision makers that innovation is a desirable corporate focus or agenda. While this condition is reasonably obvious, it bears repeating since many management teams fail to make innovation a company focus even as they contemplate why their firms lack creative breakthroughs (Robinson \& Stern, 1997). Second, obstacles to creativity must be removed. Such barriers include overly bureaucratic infrastructures, too many layers of approval, and supervisors who are threatened by subordinate initiative. The reduction of such barriers is well reviewed by Ashkenas, Ulrich, Jick, and Kerr (1995).

With these preconditions in place, firms may then build the HR infrastructure that fosters and maintains the innovative ethos:

Communications. Is there an orchestrated communications initiative through which the priority of innovation is communicated? Do senior leaders discipline themselves to consistently communicate the innovation agenda and avoid the "crisis-of-the-week" communication pattern? Are role models of creativity publicly acknowledged through multiple media? Are upward communication channels available through which important breakthrough ideas are passed to potential senior level champions? Has management legitimated forums for the discussion of innovative ideas both in existing teams as well as in ad hoc groups? Are the time, space, and other resources available to support the effectiveness of such forums? Are channels established through which creative needs and innovative ideas can be communicated across business units and departments? Are information technology systems designed to provide easy access to information that might prompt innovative thinking? Is the physical setting designed to facilitate communication within and across teams and among organizational layers?

Staffing. Is the evidence of creativity explicitly applied as a criterion for hiring at all levels? When members are selected for major task forces, is a history of innovative contributions

\author{
Many \\ management \\ teams fail to \\ make innovation \\ a company focus \\ even as they \\ contemplate why \\ their firms lack \\ creative \\ breakthroughs.
}


As noted above, $65 \%$ of mergers and acquisitions fail to achieve the commitments that are stated to the financial community. used as a selection criterion? Are individuals transferred across business units and functions to enhance the likelihood that the resultant diversity of ideas will spawn innovation? Are people promoted who have evidenced creative capabilities or who are committed to fostering and nurturing creativity in others? Are nonhierarchical promotions (i.e., fancier titles) applied to allow creative people to continue to be creative rather than moving them to managerial roles and responsibilities?

Training and Development. Are creativity skills included in corporate-wide training initiatives? Are customers included in action learning in order to directly access customers' needs and passions? Do training efforts include competitive benchmarking to create urgency around proactive innovation? Do cross functional developmental efforts facilitate exposure to nontraditional sources of creative supply and demand? Do on-the-job developmental expectations and experiences explicitly focus on innovation? Are senior executives involved as trainers to role model and encourage openness to innovative ideas?

Measurement and Rewards. Does the firm have clear output as well as behavioral measures of creativity? Are there formal mechanisms to acknowledge and reward important creative contributions? Does the firm reward risk-taking without tolerating long-term failure? Does the reward system encourage the excitement of innovation without displacing it with extrinsic greed motives? Are rewards for innovation publicized to enhance the value of the reward to the innovator and to signal the importance of innovation as a corporate priority? Do the rewards for innovation recognize contributions of both individuals and teams? Are innovative breakthroughs quickly rewarded to enhance the motivating value of the reward?

HR can also exert strategically proactive influence in the arena of mergers and acquisitions. Defining the corporate portfolio is a fundamental mechanism by which firms strategically create their future. HR's role in merger and acquisition activities has emerged quickly over the past few years (Mirvis \& Marks, 1992; Clemente \& Greenspan, 1998).

As noted above, $65 \%$ of mergers and acquisitions fail to achieve the commitments that are stated to the financial community. The cause of these failures may occur at any phase in the acquisition process. The stages of mergers and acquisition include conceptualizing the firm's portfolio needs, identifying and selecting candidates, negotiating the deal, and integrating the two entities. HR can play an active role at each phase of the acquisition ${ }^{4}$ process.

The merger and acquisition process begins with conceptualizing the firm's portfolio logic. A key element of this logic is the ability to understand the firm's core capabilities (Prahalad \& Hamel, 1990) and the demand of the marketplace for these core capabilities. Three categories of core capabilities can be distinguished: what the firm knows (knowledge); what a firm does (skills); and how the firm thinks (culture). It may be assumed that the unique value added of the HR function is the creation and maintenance of the human element, HR has greater responsibility for conceptualizing and understanding the firm's core capabilities than any other function (with perhaps the exception of the CEO). The HR professional should then conceptualize existing portfolio deficiencies and opportunities and identify the core capabilities that might be acquired through a merger or acquisition. For example, a dominant logic in Microsoft's acquisition strategy is not just the acquisition of technological, market, or financial synergies but also the acquisition of fast and brash innovative cultures. An HR professional who is effective in this area will not be limited to a domestic perspective. In Enron Corp, HR professionals have played a central role in identifying potential merger and acquisition candidates in South America.

When a potential buyer has conceptualized its portfolio needs, it then begins the process of identifying potential candidates and making a final selection. Finding a suitable candidate requires evaluating up to 100 firms in order to find one that meets the criteria of availability, fit, and price (Krallinger, 1997).

In the process of examining firms against these criteria, HR may contribute in two primary ways. First, the technical, market, financial, cultural, and managerial capabilities of the potential seller must be evaluated. HR professionals with the knowledge to conduct internal cultural, technical, and skill audits 
should now apply that knowledge to the merger or acquisition candidate. The audit logic will be similar, although gathering data from indirect sources requires considerably greater ingenuity. Since mergers and acquisitions tend to fail not because of financial, technological, or market reasons but because of people or cultural problems (e.g., Mirvis \& Marks, 1992), HR's role in examining cultural incompatibilities is essential. Second, HR also contributes to the evaluation phase as it raises important issues during due diligence. What salary, benefits, and pension commitments does the buyer incur? What is the nature of union relations and existing contractual obligations? Should the buyer's reward system be superimposed onto the workforce of the seller? What are the strengths and weaknesses of exempt, nonexempt, and salaried workforces? Is there pending litigation between the selling firm and any of its employees? What will the staffing requirements of the combined entities be? What is the age, gender, and racial profile of the firm and what are their implications? How is the seller organized? What are potential pitfalls in merging structures? Third, HR should play an important role in determining the staffing requirements of the merger and acquisition team. The technical and interpersonal skills of the team members must be carefully selected, because it is for these reasons that deals often fall apart before they are consummated.

As the negotiation phase begins, HR again brings important value to the process. During this phase, HR has both a content role and a process role. In its content role, HR continues the in-depth probing of issues that it raised during due diligence, but now it is done opportunistically, with the potential partner seeking the highest possible selling price and with HR looking for potential problems that might influence the buying price. HR's process roles during negotiations include maintaining functional working relationships within its own company's team and with the members of the other company's negotiating team. Everything else being constant, it is better to begin the new relationship on a nonadversarial note. Thus, the creation of a merged whole that is greater than the sum of the parts begins during the negotiations. An
HR professional can facilitate this goal by being aware of key subtleties during negotiations and by helping the senior executives of both sides maintain good working relationships while keeping them insulated from irksome details. HR's process role may also include knowing the negotiating style on the other side of the table and providing negotiation training as needed to her/his own team. Finally, since the ultimate selling price is often a function of the intervention of the seller's board of directors (Cotter, Shivdasani, \& Zenner, 1997) the buyer's HR professionals should ensure their team is aware of the involvement level and historical opinions of the seller's board members.

It is at the integration phase that the majority of the $65 \%$ of merger and acquisition failures occur (Clemente \& Greenspan, 1998). While this is the phase at which merger and acquisition value is suboptimized, it is also the phase at which HR's contributions can most easily rectify the most damaging problems. These problems include allowing cynicisminducing politics instead of business logic to dominate the selection and placement of people and failing to integrate the merged cultures around critical, market-based criteria.

Two considerations are paramount in deciding which individuals get which positions: (1) ensuring that the "best" people are placed in the correct positions and (2) ensuring that the placement process is seen as fair and credible. The importance of the first consideration is obvious. Fairness and credibility of the placement process are critical to ensure that political considerations are minimized. If the placement is perceived to be tainted by politics instead of achievement and capability, cynicism sets in; capable people leave; the legitimacy of leadership is eroded; and the organization turns away from the customer and into itself.

The rules for deciding who gets what positions and for minimizing political influence are well known and straightforward but often ignored. Exact and explicit criteria about performance and capability should be specified for each relevant position in the merged or acquired unit. Considerable data should be gathered against these criteria from multiple sources including subordinates, peers, supervisors,
HR should play an important role in determining the staffing requirements of the merger and acquisition team. 
A third avenue through which HR may be strategically proactive is in linking the external market environment with key internal factors. customers, suppliers, board members, and the candidate. To the extent possible, objective (i.e., politically impartial) individuals should evaluate candidates against these criteria. Such individuals may include a team of peer executives representing both of the merging organizations, a team of internal staffing consultants such as exists at General Electric, or senior HR executives. This last step is the most difficult to do correctly because political criteria such as whom a senior line executive knows and "feels" most comfortable with have such a strong tendency to dominate placement logic. One Fortune 200 top HR executive submitted his resignation three times during a major merger. Several senior line executives demanded that their favorite candidates be placed in specific positions without meeting the predetermined performance and capability criteria better than other candidates. In order to maintain the integrity of the placement process, the senior HR executive played his ultimate hand; he resigned from the process and the company rather than succumb to subtle and not-sosubtle political pressures and threats. Luckily, in each case, the line executives backed down, and the placement process continued with full integrity and credibility.

Equally important is deciding which culture should dominate. Three assumptions are necessary to ensure that the process for deciding which culture should dominate results in optimal outcomes. First, the most important element of organizational culture is shared mindset. Second, shared mindset is a key element of corporate success and, therefore, shared mindset should be defined by the requirements of the competitive marketplace. Third, it may be the case that the dominant firm in the merger or acquisition situation has the culture that is most aligned with the demands of the marketplace. It may also be the case, however, that the less dominant firm may have a culture that is best aligned with industry success criteria. It may also be the case that neither firm has the optimal culture and that the combined cultures must be defined and created anew. The key issue is to ensure that the components of the merged or acquired entities both have the cultures required for success, whether the cultures are similar or different.

With these assumptions in place, the pro- cess for merging the two cultures is fairly straightforward. The first step is for both entities to conduct a detailed analysis of the requirements for their respective marketplaces for capital, products, and services. This analysis should include viewing the marketplace from an "HR-friendly" perspective, that is, each component of the marketplace should be addressed, asking the question: "What should be known about this component of the business environment in order to determine what culture my organization should have?" The second step is to identify the sources of competitive advantage that a firm must have, the accompanying tactical actions that a firm must execute, and the relevant measures. The third step is to identify the cultural mindset that both firms must have in order to execute their respective strategies within their respective market requirements. Fourth, the merged partners may then compare their environmental assumptions, business strategies, and required cultures. By so doing they can assess which culture should dominate.

A third avenue through which HR may be strategically proactive is in linking the external market environment with key internal factors. HR's most fundamental and important corporate role focuses on optimizing the human side of the business equation. The problem is that most HR thinking addresses only $50 \%$ of the human side of business focusing on the internal "customer"- to the exclusion of external customers. Yet, HR's ultimate goal is to link the external human requirements with the internal human capabilities, thereby optimizing the utility of both. Several implications follow from this premise.

First, the HR goal is not to make employees happy or satisfied at work; rather, the HR goal should be to make those employees happy who are happy making the marketplace happy. This makes sense; yet, people in the HR field often fail to act in accord with this supposition. For example, HR professionals support company mission statements that boldly proclaim "People are our most important asset." Not only do HR professionals themselves not entirely believe such statements, neither do employees or even the executives who penned them in the first place. (This is the stuff of which Dilbert is made.) The problem with such mission state- 
ments is that in virtually every company there are people whose leaving would be in the best interest of the company. So, management rationalizes, "Well, what we meant to say is that some of our people are our most important assets." And thus the cynicism begins. In fact what we meant to say is: "People who are happy making customers happy are our most important asset. Other people we must either convert to being happy making customers happy or make them so unhappy that they leave the firm."

A second implication is that HR adds considerable value when it creates a customerfocused corporate culture. An important aspect of HR is to enhance each employee's understanding and valuing of marketplace realities. In so doing, HR not only helps facilitate the company's reactive responses to short-term market demands, but also helps to create the organization's capability to proactively track future market directions and create products and services that either lead future markets or that respond to current demands (Cespedes, 1995).

Initial research on the practices that have greatest influence on creating customer-focused value systems suggests that HR plays a central role in creating and executing these practices (Brockbank, Yeung, \& Ulrich,1989). These practices include the following: (1) providing a free flow of information directly from buying customers through the entire organization via customer focus groups, video tapes, audio tables, in-house visits, visits by employees to customer settings, and employee involvement in market research; (2) orchestrating comprehensive communication programs with the involvement of key institutional leaders who communicate the importance of the company being unified around winning the hearts, minds, and wallets of the marketplace; (3) ensuring that measurement, rewards, training, and promotions reinforce the importance of customer focus; and (4) designing organizational structures and physical settings that facilitate team work around customer requirements.

If $\mathrm{HR}$ is to play a more effective role in linking internal capabilities with external market realities, a third implication naturally follows: HR professionals must be highly knowledgeable about the marketplace for capital, products, and services. If HR is to lead in creating a customer-focused organization, HR itself must be relentlessly and intimately knowledgeable about external customers. The HR Competency Study at the University of Michigan has provided initial findings that knowledge of competitors, customers, marketing, and sales are critical aspects of an HR professional's knowledge base (Brockbank, Ulrich, \& James, 1997). It has been furthermore suggested that a major contributor to the suboptimization in marketing activities is the lack of marketing's full integration with HR (Ballantyne, Christopher, \& Payne, 1995; Clark, Peck, Payne, \& Christopher, 1995).

In order to robustly link internal capability and external requirements, HR must not only be knowledgeable of specific customer issues but also of key aspects of the macro-societal environment including the following: basic social trends that are ultimately translated into market demands for specific products and services, changing values and meaning structures, major problems and challenges that are shared by large segments of the population, and structures of interpersonal relationships that influence buying processes (Cespedes, 1995). Within the context of these broadly defined social directions, marketing departments then work on niche analysis, short-term customer need identification, consumer communications, pricing tactics, field sales management, account management, competitive analysis, product positioning, channel management, branding, and product development. To facilitate internal and external linkages, HR should also be knowledgeable in these marketing areas, though these areas of HR contributions are secondary to the more fundamental social trend analysis.

These are agendas in which HR does not traditionally have substantial expertise or responsibility; however, if HR professionals are to become strategically proactive, this type of expertise will be increasingly required.

\section{Summary}

This article has argued that HR can add greater value by holding itself to the standards of being more strategic (as opposed to operational) and more proactive (as opposed to reactive). As HR moves from operationally
HR professionals must be highly knowledgeable about the marketplace for capital, products, and services. 
reactive to strategically proactive, it moves from a position of adding relatively less to adding relatively more to a firm's competitive advantage. Specific HR agendas and activities may be associated with each of these levels of HR as competitive advantage. This article focuses primarily on the strategically reactive and strategically proactive HR roles. Among the strategically reactive arenas of HR involvement, three stand out: linking HR tactics to specific business strategies and associated tactics, creating the culture that is necessary to execute business strategies, and providing change management techniques and processes. Three agendas that help HR meet the criteria of strategically proactive include creating the corporate culture of innovation and creativity, contributing to each phase of the merger and acquisition processes, and leading the effort to link internal capabilities to external market requirements. These are not meant to be comprehensive lists of HR contributions in each of these areas of involvement, but they are meant to be important examples of the ways in which HR can add greater value in creating competitive advantage.

Dr. Wayne Brockbank's expertise focuses on the linkages between human resource practices and business strategy, creating customer-focused organizational cultures, building competitive advantage through people, and competency development in human resource professionals. He has published widely on these topics in Human Resource Management, Harvard Business Review, Human Resource Planning, and Personnel Administrator, and has contributed numerous book chapters. He has consulted with private corporations on every continent. His clients have included Texas Instruments, General Motors, Cathay Pacific Airways, Enron, Ford, General Electric, Unilever, Abbott Laboratories, Citicorp, Xerox, Hewlett-Packard, and Perez Companc. 


\section{Appendix}

\section{Corporate HR Information Sources}

Abbott Laboratories

Air Products and Chemicals

Alcoa

Allstate

American Express

Arco

AT\&T

Banco Rio (SA)

Bank of Boston

Baxter International

Boeing

British Oxygen

Cathay Pacific Airways

Champion Paper

Citicorp

Coca Cola

Daewoo

DataCard

Dow Chemical

Dow Corning

Edison Electric

Enron

Exxon

Ford

General Motors

General Electric

Godrej Group (India)

Harley Davidson

Herman Miller

Hewlett Packard

IBM

ICI (UK)

ICICI (India)

Intel
ITT

Johnson Controls

Johnson and Johnson

Kodak

Levi Strauss

Lucent Technologies

L'Oreal

Marketing Displays International

Merck

Michcon

Motorola

Norwest

Perez Companc (SA)

Polaroid

Quantum

Raytheon

Royal Bank of Canada

Sears

Sentara Healthcare System

Sheraton Inns

Singapore Air

Singapore Civil Service

Smith Klein Beecham

Steelcase

Techint (SA)

Texas Instruments

The Timken Company

Thompson Publishing

Unilever

University Hospitals of Cleveland Walt Disney Corporation

Xerox 


\section{REFERENCES}

Ashkenas, R., Ulrich, D., Jick, T., \& Kerr, S. (1995). The boundaryless organization: breaking the chains of corporate structure. San Francisco: Jossey Bass.

Ballantyne, D., Christopher, M., \& Payne, A. (1995). Improving the quality of services marketing. Journal of Marketing Management, II: 1, 7-24.

Becker, E. \& Huselid, M (1998). High performance work systems and firm performance: A synthesis of research and managerial implications. Research in Personnel and Human Source Management. 16, 53-101.

Brockbank, W. (1995). Conflict and contradiction in corporate values. Paper presented to the Oxford Conference on Values in Business. Oxford University, Oxford, England.

Brockbank, W., Ulrich, D., \& James, C. (1997). Trends in human resource competencies. Third Conference on Human Resource Competencies. University of Michigan School of Business, Ann Arbor, Michigan.

Brockbank, W., Yeung, A., \& Ulrich, D. (1989). Cultural unity: Institutional practices and individual outcomes. Presentation at the Annual Meetings of the National Academy of Management. Washington, D.C., August.

Cascio, W. (1995). Managing human resources productivity. 5th ed. New York: McGraw-Hill.

Cespedes, F. (1995). Concurrent marketing: Integrating product, sales, and service. Boston: Harvard Business School Press.

Clark, M., Peck, H., Payne, A., \& Christopher, M. (1995). Relationship marketing: Toward a new paradigm. In A. Payne (Ed.), Advances in relationship marketing. London: Kagan Page.

Clemente, M.N. \& Greenspan, D.S. (1998). Winning at mergers and acquisitions. New York: John Wiley \& Sons, Inc..

Cotter, J.F., Shivdasani, A., \& Zenner, M. (1997). Do independent directors enhance target shareholder wealth during tender offers? Journal of
Financial Economics, 43:2,153-193.

Cox Jr., T. (1993). Cultural diversity in organization. San Francisco: Berret-Koehler.

Drucker, P. (1985). Innovation and entrepreneurship: Practice and principles. New York: HarperCollins.

Isaksen, S.G. (1987). Frontiers of creativity research. Buffalo, NY: Bearly Press.

Krallinger, J. (1997). Mergers and acquisitions: Managing the transaction. New York: McGraw-Hill.

Mirvis, P.H., \& Marks, M.L. (1992). Managing the merger. Paramaus, NJ: Prentice Hall.

Prahalad, C.K. \& Hamel, G. (1990). The core competency of the corporation. Harvard Business Review. 68:3, 79-91.

Robinson, A. \& Stern, S. (1997). Corporate creativity. San Francisco: Berrett-Koehler.

Schuler, R. (1997). Managing human resources. 6th Edition. Cincinnati: South-Western Publishing Company.

Thomas Jr., R.R. (1996). Redefining diversity. New York: AMACOM.

Towers Perrin. (1992). Priorities for competitive advantage. New York: IBM and Towers Perrin.

Ulrich, D. (1995). Shared services: From vogue to value. Human Resource Planning, 18:3, 12-24.

Ulrich, D. (1997a). Human resource champions. Harvard Business School Press.

Ulrich, D. (1997b). Measuring human resources: An overview of practice and a prescription for results. Human Resource Management, 36:3, 229-301.

Wintermantel, R. \& Mattimore, K. (1997). In the changing world of human resources: Matching measures to mission. Human Resource Management, 36:3, 337-356.

Yeung, A., \& Berman, B. (1997). Adding value through human resources: Reorienting human resources measurement. Human Resource Management, 36:3, 321-335.

Yeung, A. \& Brockbank, W. (1995) Re-engineering HR through information technology. Human Resource Planning, 18:2, 25-37.

\section{ENDNOTES}

1. Many insights about the "state-of-the-art" stem from my association with four esteemed colleagues: Dave Ulrich (University of Michigan); Steve Kerr (General Electric); Warren Wilhelm (Global Consulting Alliance); and Dick Beatty (University of Michigan). I thank them readily and gladly.

2. Nearly all of the companies listed in the Appendix focus on establishing the strategically focused culture as a key element of their HR strategy. Culture is discussed under multiple rubrics including shared mindset, shared values, organization capability, human organization, and organizational competitiveness. The underlying similarity of these concepts is that they all focus on (1) improving the organization as a whole rather than individuals or teams and (2) defining and creating the desired corporate culture rather than merely enhancing short-term knowledge and skills.

3 . In an informal survey conducted during the senior line and HR executive programs at the University of Michigan, approximately 550 executives indicated that culture and shared mindset were more important to address as dominant business challenges than were technical knowledge skills. The ratio of their relative importance was $3: 1$.

4. This section is written from the buyer's perspective. The mirror image of much of this logic is relevant for the seller. 